\title{
STRATEGI PENYEMPURNAAN IMPLEMENTASI SHARED SERVICE MULTI TOWER PADA SUBHOLDING COMMERCIAL \& TRADING PERTAMINA
}

\author{
Fadly Suterisno $^{1^{*}}$, Ningky Sasanti Munir ${ }^{2}$ \\ ${ }^{1}$ Mahasiswa Magister Manajemen, Sekolah Tinggi Manajemen PPM \\ Email: fadly.suterisno@pertamina.com \\ ${ }^{2}$ Program Studi Magister Manajemen, Sekolah Tinggi Manajemen PPM \\ Email:nky@ppm-manajemen.ac.id \\ *penulis korespondensi
}

Masuk : 25-04-2021, revisi: 18-06-2021, diterima untuk diterbitkan : 19-06-2021

\begin{abstract}
ABSTRAK
Shared Services Center (SSC) adalah paradigma baru perusahaan untuk meningkatkan efisiensi dan efektivitas dalam kegiatan pendukung bisnis. Studi menunjukkan perusahaan dengan SSC dapat mengurangi biaya hingga $30 \%$ (Richter \& Brühl, 2019). Pertamina terus bertransformasi untuk mewujudkan visi menjadi perusahaan energi kelas dunia, dengan misi "Aggressive in Upstream, Profitable in Downstream". Pertamina berinisiatif membentuk organisasi SSC sejak awal tahun 2018, yang diharapkan menjadi driver untuk mengelola kegiatan pendukung bisnis yang bersifat rutin, repetitif dan bervolume tinggi di seratus lebih anak perusahaan dan afiliasi dalam Pertamina grup. Saat ini, semua tipe pekerjaan, baik yang bersifat strategis, taktikal maupun transaksional dilakukan masingmasing entitas, sehingga banyak potensi inefisiensi dalam proses bisnisnya. Melalui SSC, semua kebutuhan bisnis yang berkaitan dengan Finance, IT, Human Capital, Asset Management serta Procurement, akan dipenuhi terlebih dahulu oleh SSC dan diberlakukan chargeback. Permasalahan strategis perusahaan yang menjadi tujuan penelitian ini adalah bagaimana business parenting opportunities serta critical success factors dari subholding C\&T dengan implementasi Pertamina Multi Tower SSC? serta kesesuaiannya dengan karakteristik SSC sendiri. Apa strategi yang sesuai untuk diimplementasikan SSC dalam rangka mendukung visi pertamina menjadi world class energy company? Dengan pendekatan studi kualitatif, semua faktor sukses kritis dari anak perusahaan terkait penunjang bisnis dapat dipenuhi oleh karakteristik SSC. SSC menjadi salah satu solusi bagi anak usaha dalam mengelola fungsi supporting.
\end{abstract}

Kata Kunci: Shared service, Business parenting opportunities, Critical success factors, Economic of scale, Cost saving

\begin{abstract}
Shared Services Center (SSC) is a new paradigm for companies to improve efficiency and effectiveness in business support activities. Studies show companies with SSC can reduce costs by up to 30\% (Richter \& Brühl, 2019). Pertamina continues to transform to realize its vision of becoming a world-class energy company, with the mission of "Aggressive in Upstream, Profitable in Downstream". Pertamina has taken the initiative by forming SSC organization since early 2018, which is expected to become a driver for managing routine, repetitive and highvolume business support activities in more than one hundred subsidiaries and affiliates in the Pertamina group. Currently, all types of work, whether strategic, tactical or transactional, are carried out by each entity, resulting in many potential inefficiencies in business processes. Through SSC, all business needs related to Finance, IT, Human Capital, Asset Management and Procurement, will be met first by SSC and a chargeback will be applied. The company's strategic issues that are the aims of this research are how are business parenting opportunities and critical success factors from subholding C\&T with the implementation of Pertamina Multi Tower SSC? As well as its compatibility with the characteristics of the SSC itself. What is the appropriate strategy for SSC to implement in order to support Pertamina's vision of becoming a world class energy company? With a qualitative study approach, all the critical success factors of the subsidiaries related to business support can be fulfilled by SSC characteristics. SSC is one of the solutions for subsidiaries in managing supporting functions.
\end{abstract}

Keywords: Shared service, Business parenting opportunities, Critical success factors, Economic of scale, Cost saving 


\section{PENDAHULUAN}

\section{Latar Belakang}

Transformasi proses bisnis dapat dilakukan melalui mekanisme standardisasi, konsolidasi, dan sentralisasi layanan bisnis dengan penerapan Shared Services Center (SSC). SSC sebagai proyek strategis yang dilakukan pada proses transformasi organisasi, dibentuk tidak hanya didasarkan oleh dorongan untuk mencapai efisiensi, namun muncul sebagai lanjutan dari tren jangka panjang akibat evaluasi organisasi menuju rasionalisasi dan standarisasi. SSC menjadi model organisasi yang berkembang pada perusahaan - perusahaan kelas dunia (Gospel \& Sako, 2010). SSC adalah paradigma baru perusahaan untuk meningkatkan efisiensi dan efektivitas dalam kegiatan pendukung bisnis. Studi menunjukkan bahwa perusahaan dengan SSC dapat mengurangi biaya hingga 30\% dibandingkan perusahaan yang menggunakan konsep organisasi konvensional (Richter \& Brühl, 2019).

Berbagai manfaat yang dapat diberikan oleh SSC untuk perusahaan antara lain pengurangan biaya, layanan yang lebih baik, peningkatan kapasitas manajemen, peningkatan efisiensi \& skala ekonomi, dan mengurangi kebutuhan personel (Helbing et al., 2013). Sementara Strikwerda (2014) mengemukakan penghematan biaya langsung dengan penerapan SSC bervariasi antara 25 dan 30\%; sebuah studi dari 500 perusahaan besar Jerman dari berbagai sektor menunjukkan bahwa setelah implementasi SSC, dimungkinkan untuk menghemat 5-30\% biaya setiap tahunnya.

PT Pertamina (Persero) merupakan Badan Usaha Milik Negara (BUMN) yang bergerak di bidang energi meliputi minyak, gas, dan energi terbarukan. Pertamina menetapkan strategi jangka panjang perusahaan untuk mendukung terwujudnya visi tersebut, yaitu "Aggressive in Upstream, Profitable in Downstream", dimana Pertamina berupaya untuk melakukan ekspansi pada bisnis hulu migas dan menjadikan bisnis sektor hilir migas lebih efisien dan menguntungkan. Untuk mewujudkan visi menjadi perusahaan energi kelas dunia, Pertamina telah melakukan inisiatif dengan membentuk organisasi SSC sejak awal tahun 2018, yang diharapkan menjadi driver untuk mengelola kegiatan pendukung bisnis yang bersifat rutin, repetitif dan bervolume tinggi di seratus lebih anak perusahaan dan afiliasi dalam Pertamina grup. Saat ini, semua tipe pekerjaan, baik yang bersifat strategis, taktikal maupun transaksional dilakukan masing-masing entitas, sehingga banyak potensi inefisiensi dalam proses bisnisnya. PT Pertamina (Persero) telah membentuk multi tower SSC dengan layanan terintegrasi secara operasional, sumber daya dan teknologi, yang mencakup Tower atau fungsi Finance, IT, Human Capital, Asset Management dan Procurement.

Commercial and Trading SubHolding merupakan bagian dari rantai kegiatan bisnis hilir Pertamina dan dijalankan melalui PT Patra Niaga. Patra Niaga dalam hal ini membawahi tiga anak perusahaan Pertamina lainnya, yaitu PT Pertamina Lubricants, PT Pertamina Retail, dan Pertamina International Marketing \& Distribution Pte Ltd. Diantara subholding lainnya, C\&T memiliki peranan strategis sebagai "face of Pertamina", yang menghadapi tantangan yang semakin meningkat dari tahun ke tahun dalam bisnis hilir migas di Indonesia. Kompleksitas bisnis yang dijalani C\&T meliputi juga dalam menghadapi para stakeholder yang sangat beragam, baik dari regulator, shareholder, konsumen, mitra, serta legislatif dan eksekutif.

Hingga saat ini, tim project implementasi SSC di Pertamina masih struggle dalam roll-out, perlu terus dilakukan peningkatan terhadap service level agreement (SLA), performance, dan beberapa aspek lainnya. Dari sisi proses, perlu dilakukan harmonisasi policy dan ratifikasi sistem tata kerja atau SOP di perusahaan; kemudian konsolidasi kontrak layanan multitower. Dari sisi teknologi, 
diperlukan penerapan single platform sistem enterprise resource planning (ERP) di Pertamina grup; serta yang krusial juga pada sisi people/karyawan, diperlukan penyesuaian organisasi dan deployment sumber daya manusia dalam rangka mendukung implementasi shared service.

Dengan diambil alihnya sebagian pekerjaan yang repetitif \& transaksional oleh SSC, diharapkan subholding C\&T bisa fokus pada tugas-tugas strategis dan mempercepat pengambilan keputusan dalam bisnis. Mengingat besarnya skala ekonomi yang akan dikelola oleh SSC seiring dengan bertambahnya anak perusahaan yang menikmati layanan SSC, diperlukan strategi yang holistik, untuk memastikan terlaksananya value creation demi mencapai semua tujuan dibentuknya SSC, yang pada akhirnya akan berdampak signifikan pada perbaikan operasional perusahaan, cost efficiency, streamline organization, dan agile business model.

\section{Rumusan Masalah}

Tujuan penelitian ini adalah memberikan strategi terbaik untuk penyempurnaan implementasi shared service di Pertamina, terutama di subholding commercial \& trading $(C \& T)$. Mengingat kompleksnya lingkungan internal anak perusahaan, beberapa permasalahan strategis yang menjadi concern adalah bagaimana business parenting opportunities \& critical success factors dari subholding C\&T dengan implementasi Pertamina Multi Tower SSC? lebih lanjut juga mengkaji bagaimana kesesuaian karakteristik SSC dengan business parenting opportunities \& critical success factors yang dibutuhkan dari SSC oleh subholding C\&T ?, serta Apa strategi yang sesuai untuk diimplementasikan SSC dalam rangka mendukung visi pertamina menjadi world class energy company?

\section{Kajian Pustaka}

\section{Strategi Tingkat Korporat}

Strategi korporat adalah strategi yang dijalankan oleh induk grup perusahaan atau holding company untuk mengatur berbagai perusahaan atau strategic business unit yang ada di bawahnya. Strategi korporat adalah strategi yang disusun dalam suatu bisnis, ketika perusahaan akan bersaing dengan cara mengubah distinctive competence menjadi competitive advantage (Campbell, et al, 2014).

\section{Value Creation}

Pada perusahaan multibisnis, perusahaan induk berperan penting dalam kreasi nilai yang akan membuat korporasi dapat bertumbuh. Untuk mengetahui apakah kreasi nilai memang terjadi, perlu diteliti lebih lanjut bagaimana karakteristik perusahaan induk, faktor sukses kritis perusahaan anak, dan peluang-peluang pengasuhan yang ada. Menurut Goold, et al (1994), terdapat empat kemungkinan perusahaan induk melakukan kreasi nilai dalam perusahaan multi bisnis; SSC adalah bentuk dari Control function and services, kreasi nilai dalam perusahaan multibisnis dilakukan oleh perusahaan induk melalui pemusatan berbagai kegiatan fungsional dan pelayanan (centralized functions and services).

\section{Parenting fit}

Di dalam pengaturan usahanya, perusahaan induk (holding) memiliki kekuasaan lebih dibandingkan dengan perusahaan anak. Namun kreasi nilai bisa menjadi penghancuran nilai bila tidak ada kesesuaian pengasuhan (parenting fit) antara perusahaan induk dan perusahaan anak (Goold, 1994). Kesesuaian pengasuhan ditentukan oleh karakteristik perusahaan induk dan karakteristik perusahaan anak. 
Perusahaan ditingkat korporat mengidentifikasi permasalahan krusial yang menyangkut bisnis apa yang akan dimasukkan dalam portofolio, pendekatan apa yang seharusnya digunakan kepada unit bisnis (company approach) agar kinerja menjadi lebih baik. Adapun pendekatan analisis yang digunakan terdiri dari beberapa komponen utama untuk melakukan penelitian tingkat kesesuaian yang dipetakan dalam parenting fit matrix (Campbell, et al,.1995), yaitu: Critical Success Factor, merupakan keseluruhan faktor sukses dari unit bisnis yang membantu meningkatkan kinerja dan menciptakan keunggulan bersaing. Parenting Opportunities, merupakan kemampuan atau potensi yang terdapat pada unit bisnis dan memungkinkan korporat untuk meningkatkan kinerja serta menciptakan nilai tambah bagi unit bisnis melalui pengaruh dan peranannya.

\section{METODE PENELITIAN}

Penelitian ini menggunakan desain penelitian deskriptif. Untuk mencapai tujuan penelitian dilakukan identifikasi atas karakteristik dari SSC, faktor-faktor sukses kritis pada anak perusahaan yang berkaitan dengan kegiatan penunjang bisnis, dan peluang pengasuhan yang ada saat ini. Untuk mengungkapkan keberagaman faktor yang diharapkan didapat, maka penelitian ini menggunakan pendekatan kualitatif.

Metode studi kasus dipilih karena metode ini sesuai dengan keadaaan peneliti yang dapat secara langsung melihat berjalannya kegiatan dalam objek penelitian, dalam hal ini organisasi poject SSC. Mengikuti Yin (2003), studi kasus dapat digambarkan sebagai bentuk empiris penelitian yang menyelidiki fenomena dalam dunia nyata, menggunakan berbagai metode untuk mengumpulkan data yang kaya secara kontekstual, dengan tujuan membangun atau memperluas teori, mengeksplorasi fenomena yang muncul atau pemahaman yang lebih baik. Oleh karena itu, pendekatan studi kasus merupakan strategi yang cocok untuk menjawab tujuan penelitian ini, yang memungkinkan pencapaian pemahaman mendalam tentang peran SSC.

Data primer diperoleh langsung dari PT Pertamina (Persero) sebagai sumber utama yang dikumpul dengan wawancara dengan pihak - pihak yang berkompeten dan observasi terhadap proses implementasi SSC di Pertamina grup, dilengkapi dengan data sekunder berupa catatan, dokumentasi yang diperoleh pada lokasi penelitian dan literatur yang ada kaitannya dengan penelitian antara lain artikel, jurnal, dan hasil penelitian yang diperoleh berkenaan dengan penelitian.

Dalam penelitian ini digunakan teknik wawancara semi terstruktur kepada narasumber setelah melakukan observasi untuk mendapatkan informasi lebih mendalam mengenai topik pembahasan yang sedang diteliti. Sejumlah narasumber kunci dipilih, diantaranya Project Leader Shared Service Center sebagai salah satu narasumber dengan dasar pertimbangan bahwa yang bersangkutan menjadi pemimpin dalam proyek implementasi Pertamina Multi Tower SSC ini sehingga diharapkan bahasan penelitian lebih komprehensif.

Langkah analisis dilakukan secara runut, diawali dengan analisis visi \& misi serta tata nilai Pertamina. Selanjutnya menganalisis karakteristik SSC \& karakteristik perusahaan anak, sehingga didapat kebutuhan anak usaha terhadap implementasi SSC, serta faktor sukses kritis yang berhubungan dengan operasionalisasi SSC. Analisis difokuskan pada adanya kesenjangan antara kesesuaian antara karakteristik SSC dengan peluang pengasuhan (bantuan yang dibutuhkan dari SSC) perusahaan anak yaitu bagaimana agar SSC bisa menghilangkan atau menutup kesenjangan yang ada. Analisis kesesuaian antara karakteristik SSC dengan faktor sukses kritis perusahaan anak juga dilakukan pada dua anak perusahaan yang berada di 
subholding C\&T, yaitu PT Pertamina Patra Niaga serta PT Pertamina Lubricants; dan pada akhirnya dirumuskan inisiatif strategi untuk menutup kesenjangan tersebut.

\section{HASIL DAN PEMBAHASAN \\ Karakteristik Shared Service Center}

SSC adalah bentuk dari intervensi induk pada perusahaan anak di lingkungan Pertamina dengan pola functional and services influence. Salah satu tujuan intervensi adalah value creation, yang mana dapat terjadi bila ada kesesuaian antara karakteristik SSC dengan isu stratejik yang dihadapi oleh perusahaan anak (parenting opportunities); serta ada kesesuaian dengan critical success factors perusahaan anak. (Goold et al, 1994). Dalam konteks spesifik unit bisnis SSC, yang berfungsi sebagai pendukung perusahaan-perusahaan anak dalam menjalankan bisnisnya, memiliki karakteristik yang dijabarkan pada bahasan berikut:

Standardize service. SSC memiliki peran penting sebagai penyedia sekaligus pengendali layanan kepada seluruh anak perusahaan. Dapat kita prediksi bahwa SSC akan mengelola kontrak yang sangat masif. Misalnya pada layanan IT, seluruh notebook/laptop yang dibutuhkan pekerja bisnis grup akan disediakan oleh SSC, plus konfigurasi serta software didalam perangkat yang dimonitor secara terpusat. Hal ini tentu saja membantu anak usaha untuk fokus memikirkan keberlangsungan bisnis intinya, dibanding direpotkan dengan hal-hal rutin/penunjang tersebut. Begitu juga layanan pada tower lainnya, yang dapat dilihat pada Gambar 1 berikut (central functions, services and resources):

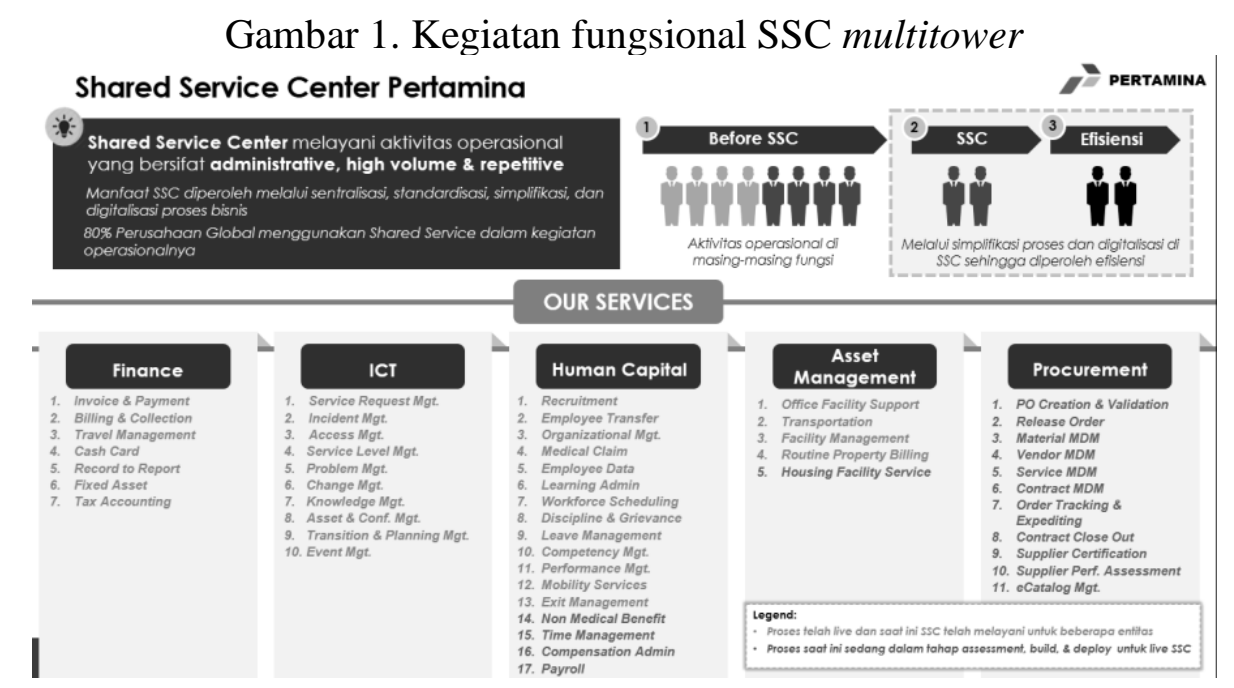

Efficient resources. SSC memberikan efisiensi sebagai hasil simplifikasi dan streamlining proses. Hal ini dilakukan dengan peningkatkan konsolidasi dan optimalisasi resources dalam Multitower SSC. Beban yang dibagi ke shared services akan membuat perusahaan tidak perlu berinvestasi besar untuk teknologi, perangkat mahal, biaya lisensi aplikasi, hingga biaya sumber daya manusia. Solusi shared services tidak hanya memberikan efisiensi operasional perusahaan saja, namun sekaligus meningkatkan kehandalan layanan. SSC akan melakukan pengawasan atas jalannya layanan yang dipimpin oleh sejumlah ahli di bidangnya. Paling tidak, payroll karyawan dalam suatu perusahaan dapat lebih efisien dengan shared resources antar perusahaan lainnya untuk tugas yang bersifat rutin, repetitif, dan bervolume tinggi.

Operational cost saving. Pekerjaan penunjang bisnis yang terdapat di seluruh anak usaha ini akan dikonsolidasikan secara terpusat, dengan harapan mendapatkan efisiensi dalam tenaga 
kerja, economic of scale dan competitive cost dari kontrak terpusat \& layanan yang terstandarisasi untuk semua unit bisnis, sinergi antar anak usaha dalam pemilihan penyedia jasa sebagai mitra utama, dan berbagai manfaat lain. Peta mental ini akan diarahkan kepada seluruh eksekutif di anak usaha untuk menjadi pedoman serta internalisasi di dalam unit bisnis masingmasing (mental maps).

Greater control. Konsolidasi proses pada suatu unit akan meningkatkan governance dan kualitas dikarenakan proses menjadi lebih mudah untuk dimonitor dan dikontrol. Selain efisiensi dari sisi orang dan teknologi, konsolidasi akan berdampak pada terjadinya konsolidasi demand yang dapat meningkatkan bargaining position perusahaan dengan pihak ketiga, yakni vendor. Pertamina melalui project SSC secara detail memetakan proses bisnis dalam suatu perusahaan atau anak usaha, untuk kemudian melakukan simplifikasi dalam proses bisnis yang bersifat rutin, repetitif, dan bervolume tinggi agar dapat disentralisasi melalui SSC. Terhadap proses bisnis inti, masih diberlakukan ketentuan otorisasi yang diatur oleh holding kepada seluruh anak perusahaan. Hal ini mencakup jenjang pejabat yang berhak melakukan komitmen atau membuat kontrak dengan nominal tertentu, serta persetujuan untuk pembayaran atas jasa yang diterima dari kontrak atau transaksi penjualan jasa bisnis, yang diatur secara hirarki dari level manager hingga ke direktur.

Higher productivity. Salah satu poin penting dalam implementasi shared services yang umum diketahui adalah pada pengelolaan SDM. Dengan shared services, perusahaan akan dibantu untuk menemukan pekerjaan mana yang berulang dan memberikan solusi untuk melakukan otomasi, yang bisa dilakukan dengan penggunaan teknologi. Pendekatan ini tentu akan menghasilkan efisiensi pada proses pekerjaan dan mengurangi biaya. Dengan diambil alihnya pekerjaan yang berulang tadi oleh penyelenggara shared services, maka perusahaan bisa fokus pada tugas-tugas strategis untuk mengembangkan talent, memaksimalkan perekrutan dan mengelola retensi karyawan. Realokasi pegawai yang biasa menyelenggarakan aktivitas fungsi support dapat dialihkan ke fungsi bisnis.

Customer centric. SSC fokus dalam memenuhi kebutuhan pelanggan dengan dukungan sistem yang mudah digunakan (user friendly). Kesepakatan antara SSC dengan pelanggan diatur dalam Service Level Agreement (SLA) yang sudah disepakati sejak awal kontrak. SLA ini mendefinisikan tingkat layanan SSC yang diharapkan, dari sisi ketepatan waktu dan kualitas. Lebih lanjut SLA juga merupakan bagian dari Key Performance Indicator (KPI) bagi SSC yang mengukur keseluruhan proses serta mengukur area kritis bagi kesuksesan SSC.

Digital solution. SSC menawarkan kepada seluruh karyawan untuk beralih ke solusi digital demi mendukung tercapainya efisiensi dan efektivitas, serta memberikan nilai tambah kepada pelanggan melalui proses-proses yang terstandarisasi dan kemampuan analisis data. Salah satu solusi yang telah dilakukan adalah penggunaan Robotic Process Automation (RPA) dalam pekerjaan rutin atau proses back office, seperti validasi dokumen, invoicing, posting ke sistem, dll; yang bisa secara efektif menggantikan peran manusia, sehingga dapat fokus pada tugas lainnya yang membutuhkan analisis stratejik.

\section{Business Parenting Opportunities dari Perusahaan Anak dengan Implementasi SSC}

Business's parenting opportunities adalah hal-hal yang dibutuhkan oleh anak perusahaan untuk sukses (Goold et al, 1994). Dalam hal ini fokus pada peluang pengasuhan yang berkaitan langsung dengan operasionalisasi SSC pada perusahaan anak, yang dapat dijabarkan pada poin berikut: 
Economic of scale. Dengan variasi bisnis yang dijalankan oleh anak perusahaan, dibutuhkan banyak penyedia jasa yang dapat membantu melakukan pekerjaan tertentu dan sesuai dengan tingkat kesukaran. Biaya yang selama ini dikeluarkan anak perusahaan tergolong cukup besar untuk operasional bisnis, ditambah lagi overhead cost yang berasal dari aktivitas penunjang. Anak perusahaan yang financing nya tidak seprima dengan perusahaan induk harus memiliki prioritas untuk mengutamakan kontrak bisnis dibanding supporting contract.

Kebutuhan anak perusahaan adalah biaya yang reasonable terhadap kebutuhan penunjang mereka. Dengan standarisasi layanan yang dilakukan oleh SSC kepada seluruh pelanggan, memberikan keuntungan tersendiri untuk membuat konsolidasi berupa kontrak terpusat atau kontrak payung berupa plafon nilai yang bisa digunakan oleh seluruh entitas bisnis, sehingga mendapatkan harga yang kompetitif bahkan lebih rendah dari pasaran, mengingat besarnya skala sebaran layanan. Hal-hal seperti ini tentu dibuttuhkan oleh anak perusahaan untuk menghemat expense. Salah satu contoh, saat ini SSC memiliki satu kontrak penyediaan kendaraan terpusat dengan satu vendor, dan digunakan pada unit bisnis Pertamina di seluruh Indonesia. Skala ekonomi bisnis inilah salah satu poin yang menjadi value yang ditawarkan SSC kepada seluruh pelanggan yang bertujuan mendapatkan efisiensi biaya, dan ini menjawab kebutuhan anak perusahaan.

Shared resource. Setiap bisnis membutuhkan aktivitas pendukung dengan banyak pekerjaan back office rutin yang berulang. Proses ini dapat di optimalkan dengan inisiatif berbagi sumber daya dengan anak usaha lainnya. Sumber daya berarti banyak hal yang dapat digunakan bersama, mulai dari tenaga kerja, infrastruktur, teknologi, dan lain sebagainya, terutama yang berkaitan dengan penunjang bisnis (IT, HC, Finance, Asset Management, Procurement). Konsep SSC membuat pekerja yang melakukan clerical task di anak perusahaan atau unit bisnis tidak diperlukan lagi, mengingat pekerjaan tersebut dipusatkan pada SSC. Konsep berbagi sumber daya ini tentunya menghemat tenaga kerja di unit bisnis, dengan mengoptimalkan jam kerja/FTE di SSC (full time equivalent); sehingga efisien dalam payroll. Hal yang perlu mitigasi adalah restrukturisasi dalam organisasi akibat dari perubahan pola ini. Tentunya akan ada relokasi pekerja ke bagian tertentu serta streamlining dalam struktur baru perusahaan.

Cost efficiency. Efisiensi biaya menjadi salah satu tujuan semua perusahaan dalam kegiatan operasional. Dengan fluktuasi kondisi ekonomi serta dinamika pasar yang sangat cepat, anak usaha akan perlu sedemikian ketat mengelola biaya operasional. Setiap tahun, anak perusahaan akan mengajukan Rencana Kerja \& Anggaran Perusahaan (RKAP) kepada perusahaan induk untuk diberikan arahan serta approval pelaksanaannya, serta dimonitor realisasinya. Dalam setiap RKAP, komponen biaya overhead menjadi sorotan, dalam artian diharapkan dapat benarbenar mengangkat bisnis perusahaan. SSC menjadi penggerak untuk secara bertahap me-reduce expenses, reduces system and infrastructure cost, dan reduce working capital.

Subsidiaries synergy. Anak perusahaan membutuhkan kebijakan, arahan, keputusan, dan dukungan induk untuk mendapatkan project yang akan menjadi pendapatan tetap bagi perusahaan anak, salah satunya melalui proses sinergi anak perusahaan, yang dapat memudahkan operasional perusahaan-perusahaan anak. Pertamina memiliki hampir semua anak usaha yang berkaitan dengan penunjang bisnis, misalnya ada PT Prima Armada Raya (PAR) untuk layanan kendaraan/mobilisasi, PT Pertamina Bina Medika (Pertamedika) yang mengelola kesehatan pekerja \& keluarga, dll. Sinergi antar unit bisnis ini akan semakin optimal dengan peran SSC sebagai koordinator layanan yang tentunya menjadikan anak usaha dalam bisnis grup sebagai mitra utama. 
Continuous improvement. Anak perusahaan membutuhkan supervisi dan arahan dari perusahaan induk untuk tetap survive. Banyak hal dalam operasional bisnis yang masih terus dapat ditingkatkan performanya. Simplifikasi dengan pengurangan beberapa prosedur, yang setelah dikaji bersama dapat diminimalisir, merupakan hal yang harus terus dilakukan anak perusahaan.

\section{Critical Success Factor dari Perusahaan Anak terhadap SSC}

Business's critical success factors adalah faktor-faktor kunci sukses yang perlu dipenuhi oleh anak perusahaan untuk sukses serta membantu meningkatkan kinerja dan menciptakan keunggulan bersaing (Goold et al, 1994). Dalam hal ini fokus pada faktor sukses kritis anak perusahaan berkaitan dengan operasionalisasi SSC:

Reliable service. Perusahaan anak yang dalam hal ini adalah pelanggan utama dari SSC, membutuhkan layanan terbaik. Seluruh layanan yang disediakan oleh SSC harus memenuhi SLA (SLA fit), berorientasi utama pada kepuasan pelanggan (customer centric), user friendly, serta proses yang standar, sehingga kesetaraan antara entitas dalam grup bisnis dapat terjaga dan harmonis (standardize service).

Streamline organization. Dalam struktur organisasi suatu perusahaan, personil yang dibutuhkan dihitung dengan banyak variabel, salah satunya adalah skala cakupan bisnis. Perusahaan akan berusaha menjalankan bisnis dengan organisasi yang slim dan streamline, namun tetap dalam performa terbaik. Trend dalam personil bisnis saat ini, perusahaan hanya diisi oleh beberapa orang saja, namun dibantu dengan automasi di berbagai bidang pekerjaan, dan task yang dilakukan oleh subvendor atau outsourcing, sehingga beban working capital perusahaan dapat seimbang dan optimal. Tentunya perusahaan akan memilih talent tertentu untuk ditambah kompetensinya, hal ini berhubungan juga dengan biaya yang harus dikeluarkan. Dengan organisasi yang compact, dan diisi oleh orang-orang yang memiliki komitmen \& performa tinggi, anak perusahaan dapat berharap tujuan bisnis nya tercapai dengan baik.

Cost efficient. Setiap perusahaan akan mengharapkan biaya operasional dalam bisnisnya dapat efektif dan efisien, dengan overhead cost yang minim dan reasonable. Dalam setiap perusahaan pun pada umumnya akan ada fungsi yang menangani bisnis utama/operasi serta fungsi penunjang (IT, Finance, HR, dll). Peran dari fungsi penunjang ini adalah sebagai pendukung aktivitas bisnis utama suatu perusahaan. Untuk operasional aktivitas pendukung ini, perusahaan akan berhitung dengan cermat, dengan mengoptimalkan seluruh sumber daya yang ada, dan akan lebih fokus pada kebutuhan core bisnisnya.

Revenue assurance. Anak perusahaan sebagai bagian dari pelaksana proses bisnis dari hulu ke hilir, tentunya membutuhkan revenue assurance untuk kesinambungan perusahaannya. Setiap anak perusahaan yang dibentuk memiliki peran tersendiri dalam suatu proses bisnis secara keseluruhan. Sinergi antar unit bisnis dibutuhkan sebagai captive market, atau pendapatan minimum yang dapat diperoleh. Misalkan Pertamina Lubricants dapat memenuhi kebutuhan pelumas bisnis seluruh anak usaha lainnya, begitu juga jasa anak perusahaan lain yang saling berkaitan kebutuhannya satu dengan yang lain.

Lean business process. Implementasi SSC harus dapat menghilangkan birokrasi dan struktur yang berpotensi menghambat proses bisnis yang berorientasi kepada pelanggan. Dengan implementasi SSC, organisasi retained dapat fokus dalam menjalankan aktifitas analitis dan strategis sebagai Center of Expertise, menjadi Business Partner yang menjalankan peran sebagai 
mitra bisnis Fungsi Operasi dan menjalankan fungsi sebagai Functional Leadership yang menetapkan policy and governance; SSC akan mengambil semua peran proses penunjang bisnis. Analisis Kesesuaian karakteristik SSC dengan Parenting Opportunities Perusahaan Anak Analisis difokuskan pada adanya kesenjangan antara kesesuaian antara karakteristik SSC dengan peluang pengasuhan (bantuan yang dibutuhkan dari SSC) perusahaan anak yaitu bagaimana agar SSC bisa menghilangkan atau menutup kesenjangan yang ada. Analisis kesesuaian dilakukan pada dua anak perusahaan yang berada di subholding C\&T, yaitu PT Pertamina Patra Niaga serta PT Pertamina Lubricants, sedangkan PT Pertamina Retail \& Pertamina International Marketing \& Distribution, Pte Ltd masuk dalam next journey dalam implementasi shared service Pertamina.

Sampai dengan saat ini tim SSC dapat menjaga SLA dengan minimal KPI 95\%, artinya tidak terdapat layanan yang missed, namun dalam perspektif yang lebih luas, dikaji setiap poin karakteristik SSC yang dihubungkan dengan bantuan yang dibutuhkan oleh anak perusahaan dari SSC. Berdasarkan asesmen, pembahasan mendalam, serta keterlibatan langsung peneliti sebagai bagian dari analyst di project SSC, serta mengikuti berbagai rapat solutif yang berisi arahan top manajemen untuk visi SSC kedepan, dapat digambarkan kesesuaian secara kualitatif pada Patra Niaga \& Pertamina Lubricants. Salah satu peran SSC yang dominan adalah untuk meminimalkan kesenjangan yang terdapat di suatu entitas terkait aktivitas penunjang bisnis dengan berbagai manfaat tambahan. Berbagai dampak signifikan didapat dari lima tower yang sudah bergabung dalam shared service.

Implementasi tower finance misalnya, dapat dilihat dari peningkatan produktivitas pekerja dalam melakukan process invoice dari vendor, ini sejalan dengan karakteristik SSC yang mendorong terwujudnya higher productivity. Efisiensi biaya juga didapat dari penurunan biaya ekspedisi pengiriman billing ke customer, sesuai dengan karakteristik SSC yang progresif untuk mendapatkan operational cost saving. Modul umum dalam tower finance berupa perjalanan dinas/ travel management, tax, invoice \& payment, billing, dan lainnya.

Beralih ke tower IT, setelah implementasi shared service IT di anak perusahaan, didapatkan potensi efisiensi dari konsolidasi \& standarisasi teknologi dan kontrak (biaya tahunan infrastruktur IT); selaras dengan tujuan SSC untuk menghasilkan cost efficiency. Penerapan IT automation process juga meningkatkan produktivitas serta sentralisasi servicedesk dengan cost reduction dari nilai kontrak eksisting. Berbagai layanan IT dengan teknologi terkini berupa digital signature, enterprise resource planning (ERP), IT supplies, cctv, telephon, dan banyak lainnya.

Lebih lanjut, implementasi shared service HC pada anak usaha menawarkan digital solution atas seluruh rutinitas terkait administrasi pekerja (mutasi, klaim kesehatan, perjalanan dinas, dll); yang berhasil meningkatkan produktivitas dan mengurangi waktu kerja yang pada proses sebelumnya dilakukan secara manual. Layanan yang dapat dinikmati anak perusahaan berupa integrated \& full cycle recruitment, payroll services, dan medical claim misalnya.

Dari tower asset management, implementasi shared service asset management di anak usaha membuat proses layanan lebih cepat \& terkontrol, karena seragam dan terpusat, serta semua histori transaksi dapat terkelola dengan baik, sehingga dapat dianalisis lebih lanjut untuk menjadi bahan pertimbangan manajemen. Misalnya pada layanan rumah dinas/housing facility services, disediakan rumah lengkap dgn furnitur \& full service sesuai budget perusahaan. Office ready to use dengan building management yang dikelola oleh tim shared service asset management. 
Dukungan mobilisasi anytime dengan kendaraan, termasuk charter pesawat untuk kebutuhan tertentu.

Untuk tower procurement, dari sisi anak perusahaan membutuhkan analisis dan pengelolaan vendor management yang handal dan trusted. Implementasi shared service procurement yang saat ini masih dalam proses pengembangan, masih terbatas pada modul vendor management. Layanan ini menawarkan proactive tracking monitor vendor performance.

Dengan semua manfaat yang didapat, kesesuaian antara karakteristik SSC dengan bantuan yang dibutuhkan dari SSC oleh perusahaan anak sangat baik. Dapat dikatakan bahwa saat ini SSC adalah spesialis dalam mengelola layanan penunjang bisnis, sehingga para pelanggan (anak usaha) sangat terbantu. Value yang ditawarkan SSC dapat diterima dengan baik oleh anak perusahaan.

\section{Analisis Kesesuaian karakteristik SSC dengan Critical Success Factor Perusahaan Anak}

Untuk memastikan berhasilnya inisiatif project SSC dalam mendukung bisnis anak perusahaan, dilakukan analisis kesesuaian antara karakteristik SSC dengan faktor sukses kritis perusahaan anak. Mengingat krusialnya CSF ini untuk setiap anak perusahaan, berikut penjabaran poin yang berkaitan dengan SSC:

Reliable service. Salah satu misi \& karakteristik SSC adalah melakukan standarisasi layanan (standardize service), serta menjadi digital solution, yang dapat menghilangkan kesenjangan yang masih terdapat pada anak perusahaan. Sebelum implementasi SSC, banyak layanan yang tidak standar atau berbeda-beda, mengakibatkan setiap anak perusahaan memiliki kontrak sendiri sesuai selera dari manajamen. Lebih dalam lagi, sebagian layanan belum memiliki waktu pemenuhan yang jelas (SLA), pencatatan dan dokumentasi serta data kegiatan layanan belum dikelola dengan baik. Kinerja SLA dan targetnya didefinisikan bersama antara SSC dan para pelanggannya. Komitmen SLA dikaitkan kepada tindakan perbaikan apabila tidak dapat dicapai. KPI dievaluasi secara rutin untuk memastikan relevansi.

Streamline organization. Organisasi SSC memiliki manager tersendiri untuk beberapa layanan yang bersifat masif, seperti manager invoice \& payment yang berfokus untuk menyelesaikan penagihan \& pembayaran kewajiban Pertamina seluruh lingkup holding \& subholding / anak perusahaan yang telah implementasi shared service finance dengan fungsi terpusat di SSC head office Jakarta; begitu juga pada tower $\mathrm{HC}$ yang memiliki manager payroll service yang mengelola penggajian pekerja, manager end user support di IT yang memenuhi kebutuhan perangkat teknologi pekerja, dan berbagai lainnya.

Cost efficient. SSC menerapkan konsep chargeback atas semua layanan yang disediakan. Biaya yang akan ditagihkan kepada pelanggan menjadi poin krusial. Biaya yang dikeluarkan pelanggan harus mencerminkan value efisiensi yang dikedepankan SSC, bersaing dengan harga pasar untuk layanan tertentu yang dapat dengan mudah disediakan oleh vendor lain. Misalnya salah satu layanan di tower general service, saat ini SSC sudah menyediakan transportasi berupa mobil sewa kepada seluruh unit bisnis Marketing Operation Region dan Refinery di seluruh Indonesia. Tipikal lokasi, kesulitan medan, dan berbagai hal lain menjadi tantangan dalam delivery layanan ini. Variabel yang menjadi pertimbangan tentunya harga, pelanggan paling tidak akan membandingkannya dengan vendor lain dengan layanan serupa. 
Revenue assurance. SSC dapat berperan sebagai pengatur agar tidak terdapat kegiatan yang sama dan/atau tumpang tindih (overlapping), sehingga dapat meningkatkan kinerja anak perusahaan dan perusahaan terafiliasi Pertamina. Kontrol ini termasuk penyelarasan bisnis agar lebih optimal dan fokus terhadap kompetensi utama setiap anak usaha. Pertamina melalui fungsi corporate business optimization mengeluarkan kebijakan penyelarasan bisnis sebagai acuan dan landasan dalam melakukan sinergi bisnis di Pertamina grup. Kebijakan ini menetapkan anak usaha yang menjadi lead dalam lini bisnis tertentu (dalam hal ini yang berhubungan langsung dengan layanan SSC multi tower).

Lean business process. SSC memiliki standar ideal dari layanan, yang sudah melewati tahap asesmen secara detail sesuai best practice dan juga disinkronisasi dengan kebutuhan bisnis korporasi secara menyeluruh. Hal ini menjadi jaminan mutu untuk setiap anak usaha yang menggunakan layanan SSC. Proses bisnis yang sederhana dan lean, tentunya sudah menjadi tujuan SSC tanpa menghilangkan esensi dari otorisasi dan governance bisnis. Dengan penggabungan dan pemusatan tim yang memiliki pekerjaan serupa di setiap anak usaha, SSC berpotensi menciptakan penghematan biaya. Kini resource yang ada di SSC dapat dimanfaatkan untuk melayani semua entitas yang telah terimplementasi.

Dengan semua faktor sukses kritis dari anak perusahaan terkait penunjang bisnis yang dapat dipenuhi oleh karakteristik SSC, dapat dikatakan bahwa SSC menjadi salah satu solusi bagi anak usaha dalam mengelola fungsi supporting, serta membantu operasional bisnis dengan berbagai value yang ditawarkan; terutama dalam faktor revenue assurance, harapan dari anak perusahaan tentunya SSC mulai menjadi eksekutor untuk semua sinergi bisnis antar anak usaha sesuai dengan konfigurasi yang telah ditetapkan holding Pertamina.

\section{Business Fit Matrix}

Parenting Fit Matrix, merupakan pemetaan unit bisnis yang membantu menggambarkan posisi seluruh unit bisnis dalam portofolio bisnis dari suatu perusahaan, dimana setiap posisi tersebut mempunyai implikasi strategi yang berbeda bagi perkembangan strategi dimasa yang akan datang (Goold et al, 1994). Dalam hal ini, dikhususkan pada kesesuaian karakteristik SSC dengan proses bisnis di anak perusahaan. Setelah melakukan penelusuran critical success factors, parenting opportunities dan parenting characteristics kemudian dilakukan analisis parenting fit matrix. Hasil analisis horizontal axis \& vertikal axis dapat dilihat pada Tabel $1 \& 2$ berikut:

Tabel 1. Pemetaan Business Fit pada Patra Niaga

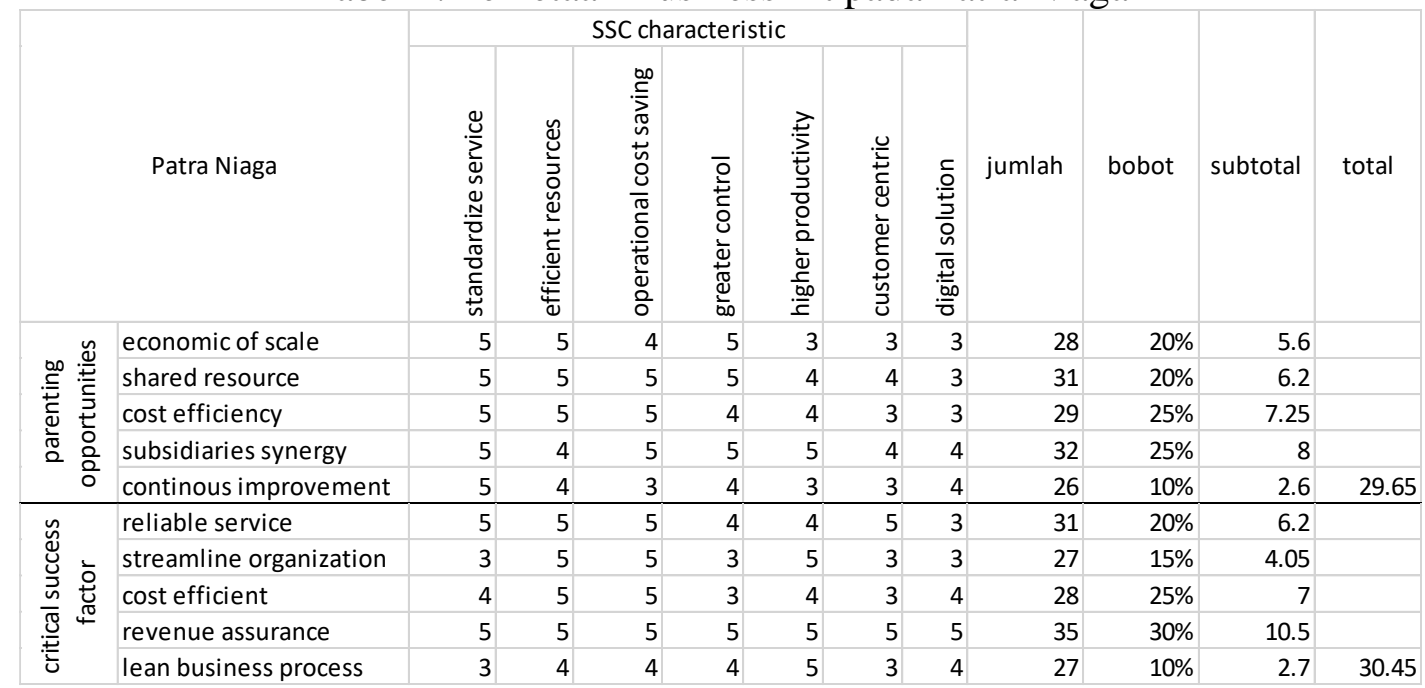


Tabel 2. Pemetaan Business Fit pada Pertamina Lubricants

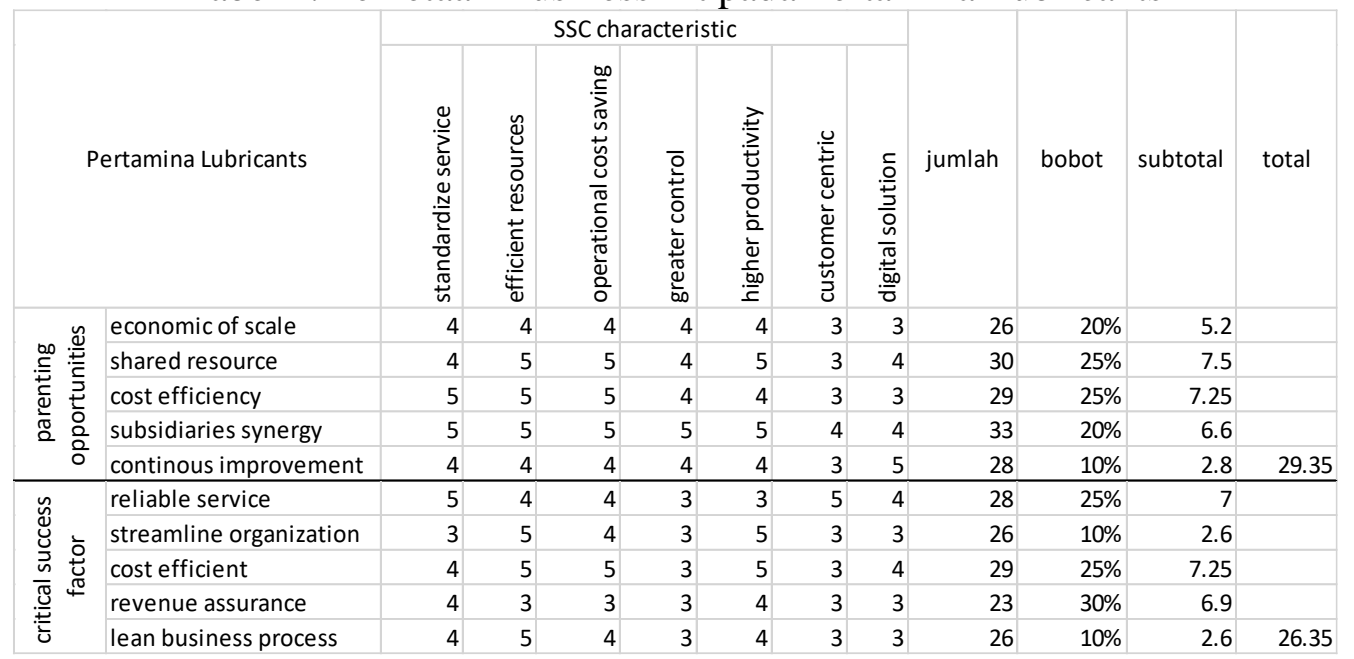

Gambar 2. Business fit matrix implementasi SSC pada Patra Niaga \& Pertamina Lubricants

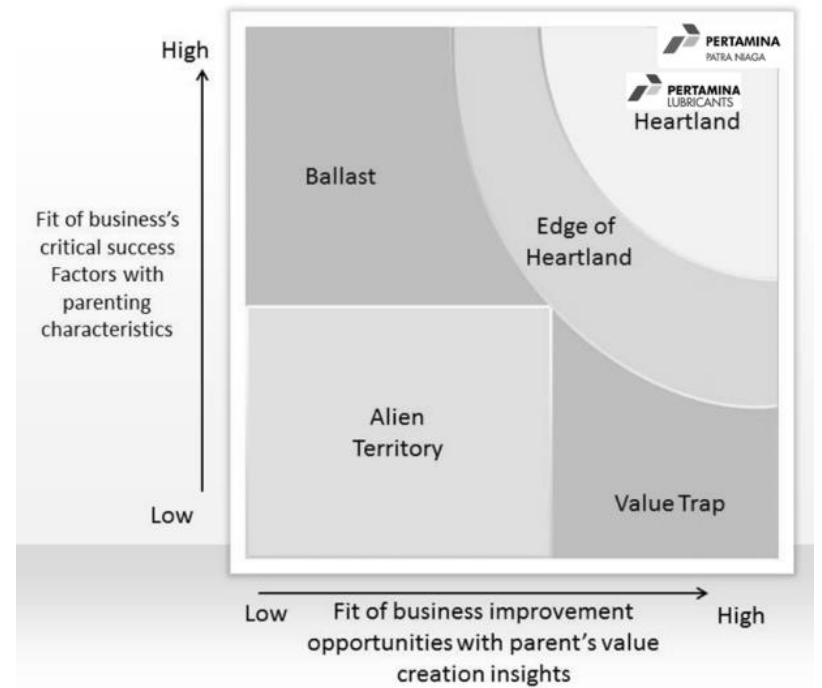

\section{Inisiatif Strategi}

Strategi yang harus dipertahankan Pertamina dalam implementasi SSC adalah memisahkan tugas taktis bernilai rendah dari fungsi strategis yang bernilai lebih tinggi. Pemilihan aktivitas dan desain utama untuk menentukan aktivitas mana yang akan dilakukan oleh SSC atau tetap ada di organisasi yang dipertahankan (retained organization). Beberapa kriteria dalam pemilihan aktivitas yang akan dilakukan oleh Shared Services Center, diantaranya adalah: aktivitas dan transaksi dengan jumlah tinggi, aktivitas yang repetitif dan rutin serta tidak membutuhkan persyaratan spesifik dalam menjalankan aktivitas bisnis.

Dalam operasionalnya, SSC memegang kontrak masif yang menjadi peluang sinergi dengan prioritas eksekutor kontrak adalah sesama anak perusahaan. SSC juga harus memanfaatkan economic of scale dengan optimal, sesuai dengan strategic fit. Untuk tower yang sifat layanannya ada direct delivery jasa berupa barang (misalnya layanan kendaraan pool untuk mobilisasi dalam \& luar kota di tower asset management, atau IT supplies untuk para end user); tetap dibutuhkan personil SSC yang melekat pada unit bisnis setempat. Namun karena sifat layanan yang umum, organisasi dalam satu unit bisnis dapat menggabungkan seluruh tower dalam satu manager. Sehingga branding SSC dapat lebih cepat dan dikenal dengan seluruh layanannya (IT \& AM). Dalam hal ini, SSC memberikan standar yang jelas dan seragam dengan 
seluruh unit bisnis untuk tim yang berada di site. Model hub \& spoke ini menjadi concern tim SSC untuk tetap prima dalam memenuhi kebutuhan bisnis.

Untuk jangka panjang, SSC perlu memikirkan rencana spin off agar dapat mengelola keuangan dengan real, dengan menghitung secara detil biaya yang dikeluarkan, dibandingkan dengan chargeback, sehingga dapat dihitung cost saving yang didapat secara menyeluruh. Mengingat banyaknya anak perusahaan Pertamina yang sudah eksis, dapat dipilih atau diakusisi salah satu anak usaha yang akan dijadikan vehicle dalam operasional, tentunya dengan nature bisnis yang sama. Model Corporate Unit Spin Off ini dapat dilakukan dengan hal yang perlu diperhatikan adalah bahwa entitas ini harus mampu bersaing dengan perusahaan sejenis lainnya yang juga mampu menawarkan jasa-jasanya kepada kelompok organisasi yang melepas unit usahanya tersebut.

\section{KESIMPULAN DAN SARAN}

Kesimpulan yang dapat diambil berdsarkan penelitian ini adalah sebagai berikut:

1. Anak perusahaan yang tergabung dalam subholding C\&T membutuhkan hal tertentu untuk sukses. Dalam hal ini operasionalisasi SSC dapat membantu dengan lima poin yaitu: economic of scale, untuk mendapatkan biaya yang wajar dalam kebutuhan penunjang bisnis; shared resource, potensi penghematan besar yang akan didapat dari berbagai sumber daya yang dapat digunakan bersama (tenaga kerja, infrastruktur, teknologi, dll); cost efficiency, biaya overhead dapat diminimalisir, sekaligus mengurangi pengeluaran terhadap biaya sistem, infrastruktur, working capital, dll; subsidiaries synergy, kebijakan dari induk yang akan menjadi pendapatan tetap bagi anak usaha; dan continuous improvement, optimalisasi proses bisnis sejalan dengan operasional.

2. Faktor kunci sukses yang perlu dipenuhi oleh anak perusahaan, yang berkaitan dengan operasionalisasi SSC ada pada lima poin berikut: reliable service, layanan yang memenuhi SLA \& berorientasi pada pelanggan dan standar; streamline organization, organisasi yang compact \& berisi semua pekerja dengan performa tinggi; cost efficient, pengalihan tugas penunjang bisnis \& berbagi biaya dengan anak usaha lain; revenue assurance, sinergi antar unit bisnis sebagai captive market; lean business process, menyederahanakan birokrasi dalam proses bisnis dengan governance yang standar.

3. Dengan semua faktor sukses kritis dari anak perusahaan terkait penunjang bisnis yang dapat dipenuhi oleh karakteristik SSC berupa standardize service, efficient resource, operational cost saving, greater control, higher productivity, customer centric dan digital solution; serta kesesuaian yang tinggi dengan parenting opportunities (bantuan yang dibutuhkan dari SSC), dapat dikatakan bahwa SSC menjadi salah satu solusi bagi anak usaha dalam mengelola fungsi supporting, serta membantu operasional bisnis dengan berbagai value yang ditawarkan; terutama dalam faktor revenue assurance, harapan dari anak perusahaan tentunya SSC mulai menjadi eksekutor untuk semua sinergi bisnis antar anak usaha sesuai dengan konfigurasi yang telah ditetapkan holding Pertamina.

Dengan diambil alihnya sebagian pekerjaan yang repetitif \& transaksional oleh SSC, diharapkan subholding C\&T bisa fokus pada tugas-tugas strategis dan mempercepat pengambilan keputusan dalam bisnis. Tanggung jawab dan otorisasi dalam pengelolaan biaya, kualitas dan ketepatan jasa yang diberikan kepada divisi Service, Performance \& Governance yang memiliki wewenang untuk melakuan pengawasan dan monitoring kinerja masing-masing team di organisasi SSC. 


\section{Ucapan Terima Kasih (Acknowledgement)}

Penulis berterima kasih kepada seluruh pihak yang telah mendukung penelitian ini, terutama Dosen Pembimbing, Ibu Dr. Ningky Sasanti Munir, MBA, yang telah membuka jendela baru untuk penulis melihat gambaran dalam dunia akademisi; serta keluarga kecil penulis istri (dr. Irma, MPH) dan dua malaikat kecil (Mihrimah \& Madeleine) yang malam malam nya berbagi dengan WFH selama setahun terakhir.

\section{REFERENSI}

Alexander, Campbell, and Goold (1994). Corporate-Level Strategy: Creating Value in the Multibusiness Company. John Wiley

Campbell, A., M. Goold, dan M. Alexander. (1995). Corporate strategy: The quest for parenting advantage. Harvard Business Review (March-April): 120-132.

Fred R David, Forest R David. Strategic Management Concept and Cases. New Jersey: Pearson, 2015.

Gurkov, I. (2015). Corporate Parenting Styles of the Multinational Corporation: A Subsidiary View. International Business Research, 10, 57-78. https://doi.org/10.1108/S1745 88622015000001000357

Helbing, F., Rau, T., \& Riedel, A. (2013). Future trends in finance shared services organisations. In F. Keuper, \& K.-E. Lueg (Eds.), Finance bundling and finance transformation.

Joha, A. and Janssen, M. (2014), "Factors influencing the shaping of shared services business models : Balancing customization and standardization", Strategic Outsourcing: An International Journal Vol. 7 No. 1, 2014 pp. 47-65. Emerald Group Publishing Limited

Joseph Soalheira Greg Timbrell . "What is Shared Services?" In Shared Services as a New Organizational Form. Published online: 08 Oct 2014; 67-84. http://dx.doi.org/10.1108/S1877-636120140000013004

Kanter, R. M. (1998). Achieving Synergies. In Goold, M. \& K.S. Luchs (Eds.), Managing the Multibusiness Company: Strategic Issues for Diversified Groups(pp 240-255). London: Routledge.

Management Accounting Committee. (2000). Implementing Shared Services Centers. New Jersey: Institute of Management Accountants.

PT Pertamina Lubricants. (2017). Integrated Annual Report 2017. Jakarta: PT Pertamina Lubricants.

PT Pertamina Patra Niaga. (2018). Laporan Tahunan 2018: Energizing Our Nation. Jakarta: PT Pertamina Patra Niaga.

PT Pertamina (Persero). (2019). Laporan Tahunan 2019: Energizing Our Nation. Jakarta: PT Pertamina (Persero).

Richter, P. C., \& Brühl, R. (2019). Ahead of the game: Antecedents for the success of shared service centers. European Management Journal, 38(3), 477-488.

Sako, H. G. (2010). The unbundling of corporate functions: the evolution of shared services and outsourcing in human resource management. Journal of Industrial and Corporate Change, $19(5), 1367-1396$.

Strikwerda, J. (2014). Shared service centers: From cost savings to new ways of value creation and business administration. In Bondarouk, T. (Ed.). Shared Services as a New Organizational Form Advanced Series in Management, 13(1), 1-15. doi:10.1108/S1877636120140000013000

White, Collin. Strategic Management. New York: Palgrave Macmillan, 2004

Yin, R. K. (2003). Case study research: Design and methods (3rd ed.). Thousand Oaks, CA: Sage. 